\title{
Central Corneal Thickness and its Relationship with Myopia
}

\author{
Jamil Ahmed and Mohammad Feroz Memon
}

\begin{abstract}
OBJECTIVE: To study the relationship between central corneal thickness (CCT) and degree of myopia.

DESIGN: A descriptive study.

SETTING: Department of Ophthalmology, Isra University Hospital Hyderabad, Sindh - Pakistan from January to May 2004.

METHODS: One hundred and fifty four (154) subjects were recruited from a Refractive Surgery Clinic. Patients were divided into two groups depending upon the degree of myopia. Group I comprised of patients having myopia between -0.50 to -5.00 diopters (D) while Group II comprised of myopic patients having myopia > -5.25 (D). CCT was measured in both eyes of each subject using ultrasonic pachymeter and data from right eye was selected for analysis. The CCT was correlated with the degree of myopia in diopters using Pearson's correlation coefficient and student - $\mathrm{t}$ - test with multiple comparisons.

RESULTS: Mean CCT in group I was 537.49 micron $(\mu \mathrm{m})(\mathrm{SD}+33.74)$ and in group II was 534.56 $\mu \mathrm{m}(\mathrm{SD}+34.03)$. The mean CCT showed no statistical difference between two groups $(P>0.05)$ CONCLUSION: The CCT was not correlated with the degree of myopia.
\end{abstract}

KEY WORDS: Central corneal thickness. Myopia. Pachymeter.

\section{INTRODUCTION}

The prevalence of myopia in young adolescent eye has increased substantially over recent decades and is now approaching $10-25 \%$ and $60-80 \%$ in industrialized societies of the West and East respectively. ${ }^{1}$ Studies conducted in sub-continent also confirmed the high prevalence of myopia among young adults.- ${ }^{2,3}$ Worldwide, the condition is considered to be the leading cause of visual impairment. ${ }^{4}$ With increasing rate of myopia, refractive surgery such as Laser in situ keratomaleusis (LASIK) has become popular in Asia. When undertaking such surgery to correct myopia, the central corneal thickness (CCT) is an important consideration in order to prevent the cornea being too thin after treatment. Studies have attempted to investigate the effect of refractive error on CCT. Prince, et $\mathrm{al}^{5}$ Touzeau, et $\mathrm{al}^{6}$ and Lene, et $\mathrm{al}^{7}$ among others looked for a connection between CCT and myopia. Measurements were taken with different types of pachymeters and with different set ups and with inconclusive results. The objective of this study was to investigate the relationship between CCT with the degree of myopia in myopia adults who were being assessed for refractive surgery.

\section{SUBJECTS AND METHODS}

Study consisted of 154 myopic patients who presented for LASIK assessment at the Department of
Ophthalmology, Isra University Hospital Hyderabad, Sindh - Pakistan. Subjects were conveniently enrolled for the study and data were collected through specially designed proforma. Subjects with previous eye surgery, glaucoma, diabetics or other acute or chronic disease possibly affecting the corneal thickness were excluded. Patients were divided into two groups according to the preoperative spherical equivalent refraction. Group I contained eyes from -0.50 Diopter (D) to $-5.00 \mathrm{D}$ and group II contained eyes from -5.25 $\mathrm{D}$ and greater. Manifest refraction and CCT measurements with ultrasound pachymeter were performed in both eyes of all patients. After instillation of a drop of $0.5 \%$ proparacaine, the corneoscan probe was placed perpendicularly on the central cornea using DGH 1000 ultrasonic pachymeter. Three readings were obtained and averaged.

\section{STATISTICAL ANALYSIS}

Calculated descriptive statistics were tabulated by mean and standard deviation (SD). Pearsons' correlation analysis was performed to evaluate the relationship between degree of myopia and CCT. Student ttest was used to compare CCT and the groups of myopia. Data were analyzed using statistical package for social sciences version 11.0 (SPSS Chicago, Illinois) and statistical significance was assumed at the $\mathrm{P}<0.05$ level. 


\section{RESULTS}

One hundred and fifty four (154) patients were evaluated. There were 84 females $(54.50 \%)$ and 70 males $(45.50 \%)$ with the mean age of $25.75+6.9$ years (range 14-50 years) (Table I). Only data from right eye were used in the analysis. The mean CCT was $535.68+33.84$ Micron $(\mu \mathrm{m})$ ranged from $418 \mu \mathrm{m}$ to $623 \mu \mathrm{m}$ (Table II). The mean CCT of group I was $537.49 \mu \mathrm{m}$ and the mean CCT of group II was 534.56 $\mu \mathrm{m}$. There was negative correlation between CCT and the degree of myopic spherical equivalent ( $r=-0.107)$, when the central corneal thickness was split into groups and compared with degree of myopia that was not significant $(P=0.604)$. Table III shows the comparison of means in myopic groups and CCT.

TABLE I: DEMOGRAPHIC FEATURES ( $n=154)$

\begin{tabular}{|l|l|}
\hline \multicolumn{1}{|c|}{ Gender } & Number of Subjects (\%) \\
\hline Male & $70(45.50 \%)$ \\
Female & $84(54.50 \%)$ \\
\hline Age (Years) & \\
Mean + SD & $25.75+6.9$ \\
Range & $14-----50$ \\
\hline
\end{tabular}

TABLE II:

CORNEAL THICKNESS OF ALL PATIENTS

\begin{tabular}{|l|l|}
\hline Mean & $535.68 \mu \mathrm{m}(+33.84)$ \\
Range & 418 ----- 623 \\
\hline
\end{tabular}

TABLE III:

COMPARISON OF MYOPIC GROUPS AND MEAN CCT

\begin{tabular}{|l|c|c|}
\hline Myopic group & $\begin{array}{c}\text { Number of } \\
\text { Patients }\end{array}$ & Mean CCT (SD) \\
\hline Group I & 59 & $537.49(+33.74)$ \\
\hline Group II & 95 & $534.56(+34.03)$ \\
\hline
\end{tabular}

\section{DISCUSSION}

Numerous studies have been carried out to determine a connection between CCT and myopia. VonBahr was the first who generated interest in this subject and reported thinner cornea in myopia of less than $-4 D^{8} .^{8}$ In this study, the average corneal thickness was 537.49 $\mu \mathrm{m}(+33.74)$ and $534.56 \mu \mathrm{m}(+34.03)$ in group I and group II respectively being slightly thinner in high myopes. Kunert, et $\mathrm{al}^{9}$ reported thinner cornea $(518.23 \mu \mathrm{m}$ to $520 / \mu \mathrm{m})$ in Indian myopic patients. They also reported that the corneal thickness increased as the myopia increased. Another study ${ }^{10}$ also favors the results of Indian study which showed corneal thickness of moderate and high myopia was thicker than hyperopia and emmetropia. However, $\mathrm{P}$ Lene, et $\mathrm{al}^{11}$ who used optical low coherence reflectometry (OLCR) Pachymeter which has precision of about $1 \mu \mathrm{m}$ (SD) and intrasession reproducibility around 0.9-1.2 $\mu \mathrm{m}$ and $a$ high intersession reproducibility ${ }^{12}$ found no statistical significant difference between emmetropia and myopia even though the corneal thickness was thinner in myopic patients. The mean CCT in this study was close to that found in Chang $\mathrm{W}^{13}$ and F. Hau Bor, et al 14 studies which were $533 \mu \mathrm{m}$ and $538 \mu \mathrm{m}$ respectively. However, in the study by Prince ${ }^{15}$ in which subjects were Caucasian, the mean CCT was thicker (550 $\mu \mathrm{m})$. Recently, Vijaya, et $\mathrm{al}^{16}$ has reported the mean CCT in a normal rural South Indian population to be $505.9 \mu \mathrm{m}$ (SD: 31.1). Further racial variation in CCT has been reported in African and Japanese having thinner cornea on average compared to Caucasian, Filipinos Chinese and Hispanics. ${ }^{17}$ Studies conducted in India showed thinner cornea than our study. Being living in the same region, this difference in CCT is quite amazing. This difference might be due to different methods used in taking measurement of corneal thickness. Out of 154 patients, group I consisted of 59 patients and group II consisted of 95 patients. The disparity of numbers between two groups may be related to the dependency of patients for spectacle in high myopic patients that is why high myopes seek treatment of myopia more frequently than the low myopes. The relationship of CCT and intraocular pressure was investigated recently. It has been reported that intraocular pressure may be higher in myopic than non-myopic eyes ${ }^{18}$ and corneal thickness may be important in this context. This indicates that caution should be exercised in interpreting risk of glaucoma associated with myopia with thin cornea. There are a few limitations in this study. The axial lengths of the subject have not been measured to differentiate axial myopia from index myopia. However, every subject had gone through complete ophthalmologic examination and such subjects are not expected to have index myopia. We did not utilize an emmetropic sample for comparison; however, we tried to compare our data with studies from the Southeast Asian region. The results of this study show a difference of $2.93 \mu \mathrm{m}$ between two groups (the high myopic being the thinner). Although the difference is very small a large sample size may be needed in order to get meaningful results. In conclusion, this study showed no statistically significant difference between the mean CCT of low myopia (Group I) and of high myopia (Group II); however CCT seems to be lesser compared to reported values in Caucasian subjects and thicker than the Indian sub- 
jects. This information may be useful for refractive surgeons when selecting patients for refractive surgery.

\section{REFERENCES}

1. Saw SM. A synopsis of the prevalence, rates and environmental risk factors for myopia. Clin Exp Optom. 2003; 86:289-94.

2. Boorne R, Dineen B, Jadoon Z, Lee PS, Khan A, Johson $G J$, et al. The national blindness and visual impairment survey - research design, eye examination, methodology and results of the pilot study. Ophthalmic Epidemiol. 2005; 12(5): 321-33.

3. Dandona R, Dandona L, Srinivas M, Sahare P, Narsaiah S, Munoz SR, et al. Refractive error in children in a rural population in India. Invest Ophthalmol Vis Sci. 2002; 43(3) : 615-22.

4. World Health Organization. Elimination of avoidable visual disabilities due to Refractive Errors (WHO/PBL/OO79). Geneva; World Health Organization 2000. Vision 2020: Available at: http:// www.v2020.org/html/sigh.html.

5. Prince FW Jr, Koller DL and Prince MO. Central corneal pachymetry in patients undergoing laser in situ keratomileusis. Ophthalmology. 1999; 106:2216-20.

6. Touzeau O, Allouch C, Borderie V, Kopito R, Laroche L. Correlation of refraction and ocular biometrics. J Fr Ophthalmology. 2003; 206: 355-63.

7. Lene $P$, Jesper $H$, Niels $E$. Central corneal thickness in high myopia. Acta Ophthalmol Scand. 2005; 83: 539-42.

8. VinBahr G. Corneal thickness: its measurement and change. Am J Ophthalmol. 1956: 916-20.

9. Kunert KS, Bhartiya P, Tandon R, Data T, Christian $\mathrm{H}$, Vajpayee RB. Central corneal thickness in Indian patients undergoing LASIK for myopia. J Refact Surg 2003; 19:378-79.
10. Nomura $H$, Ando F, Niino N, Shimokata H, Miyake $Y$. The relationship between intraocular pressure and refractive error adjusting for age and central corneal thickness. Ophthalmic and Physiological Optics. 2004; 24 (1);41-45.

11. Pedevsen L, Hjortdal J, Ehlers N. Central corneal thickness in high myopia. Acta Ophthalmol Scand. 2005; 83: 539-42.

12. Bohnke M, Master BR, Walti R, Ballif JJ, Charanne $\mathrm{P}$, Gianotti $\mathrm{R}$, et al. Precision and reproducibility of measurement of human corneal thickness with rapid optical low-coherence reflectometry. J Biomed Opt. 1999; 4:152-56.

13. Chang SW, Tsai IL, Hu FR, Lin LL, Shin YF. The cornea in young myopic adult. $\mathrm{Br} \mathrm{J}$ Ophthalmol. 2001; 85:916-20.

14. Fam HB, How ACS, Bastaran M, Lim KL, Chan $\mathrm{YH}$, Aung T. Central corneal thickness and its relationship with myopia in Chinese adults. $\mathrm{Br} \mathrm{J}$ Ophthalmol. 2006; 90:1451- 53.

15. Prince FW Jr, Koller DL, Prince MO. Central corneal pachymetery in patients undergoing laser in site Keratomileusis. Ophthalmology. 1993; 106:2216-20.

16. Vijaya L, George R, Paul PG, Baskeran M, Arivind Het Raju P, et al. Prevalence of open angle glaucoma in a rural south Indian population. Invest Ophthalmol Vis Sci. 2005; 46(12): 4461-67.

17. Aghaian E, Choe JE, Lin S, Stamper RL. Central corneal thickness of Caucasians, Chinese, Hispanics, Filipinos, African, Americans and Japanese in a glaucoma clinic. Ophthalmology. 2004; 111:2211-19.

18. Quinn GE, Berlin JA, Young TL, Ziylan S, Stone RA. Association of intraocular pressure and myopia in children. Ophthalmology. 1995;102:180-85.

$$
\begin{aligned}
& \text { AUTHOR AFFILIATION: } \\
& \text { Dr. Jamil Ahmed (Corresponding Author) } \\
& \text { Assistant Professor } \\
& \text { Department of Ophthalmology } \\
& \text { Isra University Hospital } \\
& \text { Hala Road Hyderabad, Sindh-Pakistan. } \\
& \text { E-mail: drsja@hotmail.com } \\
& \text { Dr. Mohammad Feroz Memon } \\
& \text { Assistant Professor } \\
& \text { Department of Ophthalmology } \\
& \text { Isra University Hospital } \\
& \text { Hala Road Hyderabad, Sindh-Pakistan. }
\end{aligned}
$$

